\title{
Professor Brigitta M. Peskar MD (1942-2012)
}

\author{
K. D. Rainsford
}

Received: 4 August 2012/ Accepted: 6 August 2012/Published online: 8 September 2012

(C) Springer Basel AG 2012

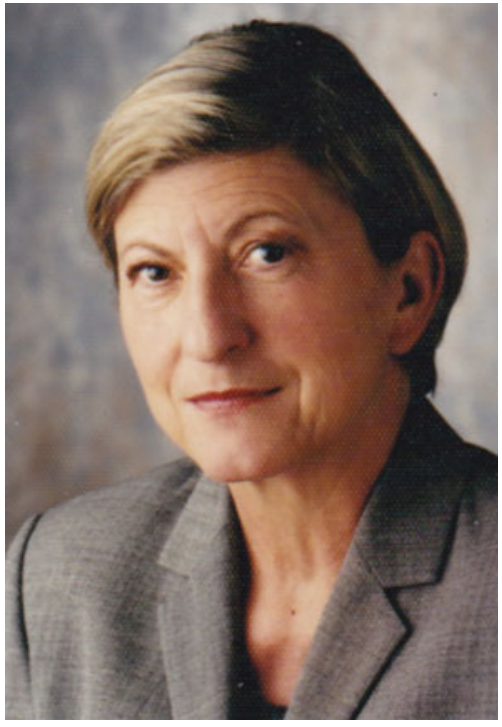

Professor Brigitta M. Peskar. Photograph kindly provided by Professor Bernhard M. Peskar.

It is with much sadness that we report the untimely death on Thursday June 14, at Vienna of Professor Brigitta M. Peskar from pancreatic cancer. Brigitta was an outstanding experimental gastroenterologist-pharmacologist with a highly distinguished publication record of over 200 original research publications, and an extensive number of excellent reviews and book chapters encompassing the fields of prostaglandins, leukotrienes and lipoxins in the

\section{K. D. Rainsford ( $\square)$}

Emeritus Professor of Biomedical Sciences,

Sheffield Hallam University, Howard Street,

Sheffield S1 1WB, UK

e-mail: k.d.rainsford@shu.ac.uk regulation of gastrointestinal mucosal ulceration and diseases, the actions of anti-inflammatory drugs on the production of these eicosanoids, and the roles of eicosanoid metabolism in various inflammatory bowel diseases. Brigitta was also recognized as a distinguished physicianscientist, combining the unique attributes of an excellent diagnostic gastrointestinal physician with insight into the leading issues in clinical-experimental gastroenterology.

Brigitta Lutz was born in 1942 in Munich (Germany); for her family and herself, the wartime and post-war conditions in Germany must have been very difficult. From 1951 to 1960 she was in secondary school at Ried in Upper Austria, whereupon she entered the University of Vienna to study jurisprudence. During 1963-1970 she studied medicine at the University of Vienna, graduating as an MD with the highest honour "Sub auspiciis praesidentis rei publicae". She married Dr. (now Prof.) Bernhard A. Peskar, $\mathrm{MD}$, in 1968 and this was to be the beginnings of an outstanding husband-wife collaboration, which extended through both their careers.

In 1970, Brigitta won a Fulbright scholarship to work with Professor L. Levine at Brandeis University. Upon completion of this distinguished research position in 1971 she returned to the University of Vienna to undertake an internship in the Departments of Medicine and Gastroenterology. In 1973 she followed her husband to the University of Freiburg (Germany) where she worked at the Department of Internal Medicine and was from 1974 to 1979 a ward physician in that department. In 1977 she received her Habilitation in Internal Medicine. In 1978, she received the distinguished Thannhauser Award for scientific achievements in the field of gastroenterology. From 1979 Brigitta held a Heisenberg Scholarship from the West German Ministry of Science in the Department of Gastroenterology of the University of Freiburg (until 1981) and 
then in the Department of Gastroenterology at Essen (until 1984). At this stage Brigitta had begun formative studies involving the development of radio-immuno assays (RIA) for prostaglandins and their application for studying the effects of anti-inflammatory drugs as well as the anti-ulcer mucus-stimulating drug, carbenoxolone on mucosal production of cytoprotective prostaglandins. The work that she did with Bernhard in developing highly sensitive and specific RIA was fundamental to defining the actions of drugs and changes in prostaglandin metabolism in intestinal inflammatory diseases. Indeed, there are an impressive number of citations to papers by the Peskars on the development of RIAs and their application in determining changes in PGs in ulcer disease both in clinical conditions as well as in experimentally induced models.

Little known is the fact that at this early stage in their work on developing RIAs, Brigitta and Bernhard were very generous to scientific colleagues in sharing knowledge about the techniques as well as with generous gifts of reagents.

In 1985, Brigitta was appointed Professor and Head of the Department of Experimental Clinical Medicine, Medical Faculty of the Ruhr University of Bochum (Germany) until she retired in 2007. Here she extended her research interests into the examination of PGs and other aspects of eicosanoid metabolism in a wide variety of experimental ulcer models (ethanol-, acid-induced, ischaemia-reperfusion) and those involving the manipulation of, or the regulation of nitric oxide production and the protective effects of lipoxins. She also undertook important collaborative studies with Professor Fred Halter and his group (Inselspital, Dept. of Gastroenterology, University of Bern,
Switzerland) on the importance and role of cyclooxygenase-2 (COX-2) in ulcer healing. In many respects, these were highly significant investigations since they highlighted that gastric mucosal injury and protection were more than just effects on COX-1 and COX-2 activities in regulation of the production of PGs and other metabolites. Even this proved more challenging in studies in which she explored the effects of protein kinase C, ATP-sensitive potassium channels and phospholipase $\mathrm{C}$ in PG mediated gastroprotection. Throughout much of her research work, Brigitta judiciously employed many pharmacological agents, those used clinically as well as those available for experimental use as probes to explore the actions on production of key mediators of inflammation, cytoprotection and gastric physiology.

Many of these studies were undertaken with collaborators who were inspired by the understanding and leadership of Brigitta. She was an immensely personable individual who was quiet in her insight and critical appraisal for research, most humble and enjoyed engaging conversation on a wide range of research topics.

For her husband, Bernhard, her premature death must be a great loss of a much-valued collaborator, full of inspiring ideas, as well as a wife and friend. Our deepest regrets go to Bernhard in this sad loss.

Finally, but not least, Brigitta was a foundation member of the Editorial Board of Inflammopharmacology since its inception in 1991. Her advice on the development of the Journal and in reviewing manuscripts was, as with all her scientific approach invaluable, honest and with great integrity. 